\title{
Synthesis, Crystal Structure, and Magnetic Properties of Quaternary Iron Selenides: $\mathrm{Ba}_{2} \mathrm{FePnSe}_{5}(\mathrm{Pn}=\mathrm{Sb}, \mathrm{Bi})$
}

\author{
Jian Wang, Joshua T. Greenfield, Kirill Kovnir**
}

Department of Chemistry, University of California, Davis

One Shields Avenue, Davis, CA 95616, United States

\begin{abstract}
Two new barium iron pnictide-selenides, $\mathrm{Ba}_{2} \mathrm{FeSbSe}_{5}$ and $\mathrm{Ba}_{2} \mathrm{FeBiSe}_{5}$, were synthesized by a high-temperature solid-state route and their crystal structures were determined using single crystal X-ray diffraction. Both compounds are isomorphic to the high pressure phase $\mathrm{Ba}_{3} \mathrm{FeS}_{5}$ and crystallize in the orthorhombic space group Pnma (No. 62) with cell parameters of $a=$ 12.603(2)/12.619(2) $\AA, b=9.106(1) / 9.183(1) \AA, c=9.145(1) / 9.123(1) \AA$ and $Z=4$ for $\mathrm{Ba}_{2} \mathrm{FeSbSe}_{5}$ and $\mathrm{Ba}_{2} \mathrm{FeBiSe}_{5}$, respectively. According to differential scanning calorimetry, $\mathrm{Ba}_{2} \mathrm{FePnSe}_{5}$ compounds exhibit high thermal stability and melt congruently at $1055(5) \mathrm{K}(\mathrm{Pn}=$ $\mathrm{Sb})$ and $1105(5) \mathrm{K}(\mathrm{Pn}=\mathrm{Bi})$. Magnetic characterizations reveal strong antiferromagnetic nearestneighbor interactions in both compounds resulting in an antiferromagnetic ordering at 58(1) $\mathrm{K}$ for $\mathrm{Ba}_{2} \mathrm{FeSbSe}_{5}$ and 79(2) $\mathrm{K}$ for $\mathrm{Ba}_{2} \mathrm{FeBiSe}_{5}$. The magnetic interactions between $\mathrm{Fe}^{3+}$ centers, which are at least $6 \AA$ apart from each other, are mediated by superexchange interactions.
\end{abstract}

Keywords: Crystal structure; iron selenide; bismuth selenide; antimony selenide; antiferromagnetic semiconductor. 


\section{Introduction}

Iron selenides have attracted significant attention in recent years due to the discovery of superconductivity in $\mathrm{FeSe}^{[1]}$ and intercalation compounds such as $\mathrm{A}_{x} \mathrm{Fe}_{2} \mathrm{Se}_{2}(\mathrm{~A}=\mathrm{Na}, \mathrm{K}, \mathrm{Rb}$, $\mathrm{Cs})^{[2]}$ and $\left(\mathrm{Li}_{1-x} \mathrm{Fe}_{x}\right) \mathrm{OHFeSe}{ }^{[3]}$ The main building block in all these phases is the $\mathrm{Fe}^{\mathrm{II}} \mathrm{Se}_{4}$ tetrahedron. Compounds containing linear chains of $\mathrm{Fe}^{\mathrm{III}} \mathrm{Se}_{4}$ tetrahedra exhibit no superconductivity, but different kinds of magnetic orderings that are strongly dependent on the connectivity between the chains. ${ }^{[4,5]}$ Additional structural complexity may be introduced by combining fragments based on $\mathrm{FeSe}_{4}$ tetrahedra with other selenide fragments. For example, antimony- and bismuth-selenides exhibit rich structures due to the presence of stereoactive electron lone pair on the $\mathrm{Sb} / \mathrm{Bi}$ atoms, which add to the structural diversity of these prospective thermoelectric materials. ${ }^{[6-10]} \mathrm{A}$ variety of structures ranging from $0 \mathrm{D}$ to $3 \mathrm{D}$ were reported for ternary $\mathrm{Sb} / \mathrm{Bi}$ selenides containing alkali and alkaline-earth cations. ${ }^{[11-14]}$ In this work we have explored a combination of tetrahedral $\mathrm{FeSe}_{4}$ and flexible $(\mathrm{Sb} / \mathrm{Bi}) \mathrm{Se}_{\mathrm{x}}$ building blocks in the quaternary Ba-Fe-Pn-Se $(\mathrm{Pn}=\mathrm{Sb}, \mathrm{Bi})$ phases. Through high-temperature solid state reactions, the new compounds $\mathrm{Ba}_{2} \mathrm{FeSbSe}_{5}$ and $\mathrm{Ba}_{2} \mathrm{FeBiSe}_{5}$ were discovered as the first representatives in the Ba-Fe-Pn-Se systems. The crystal structure, thermal stability, and magnetic properties of both compounds are discussed herein.

\section{Experimental}

Synthesis. Starting materials were handled in an argon-filled glovebox with $\mathrm{O}_{2}$ level below 1 ppm. All starting materials are commercial grade and used as received: Ba rod (Sigma Aldrich, 99.9\%), Fe powder (Alfa Aesar, 99.998\%), Sb shots (Alfa Aesar, 99.9999\%), Bi chunks (Alfa Aesar, 99.999\%), and Se powder (Alfa Aesar, 99.999\%). 
The elements were loaded in carbonized silica ampoules in a molar ratio Ba:Fe:Pn:Se = 2:1:1:5 $(\mathrm{Pn}=\mathrm{Sb}, \mathrm{Bi})$. The ampoules were evacuated, torch-flame sealed, and annealed in a programmable furnace. The reaction mixture was first heated from room temperature to $1073 \mathrm{~K}$ at a rate of $45 \mathrm{~K} / \mathrm{h}$, annealed at this temperature for $144 \mathrm{~h}$; afterwards the furnace was slowly cooled down to $873 \mathrm{~K}$ within 72 hours, annealed at $873 \mathrm{~K}$ for $120 \mathrm{~h}$, and finally the furnace was turned off. The samples were ground in a mortar in the glovebox, resealed in carbonized silica ampoules, and annealed for a second time using the same temperature profile. After the second annealing the samples appeared as black air- and moisture-stable polycrystalline powders. The phase purity of the $\mathrm{Ba}_{2} \mathrm{FePnSe}_{5}$ samples was checked by powder X-ray diffraction as shown in Figure 1.

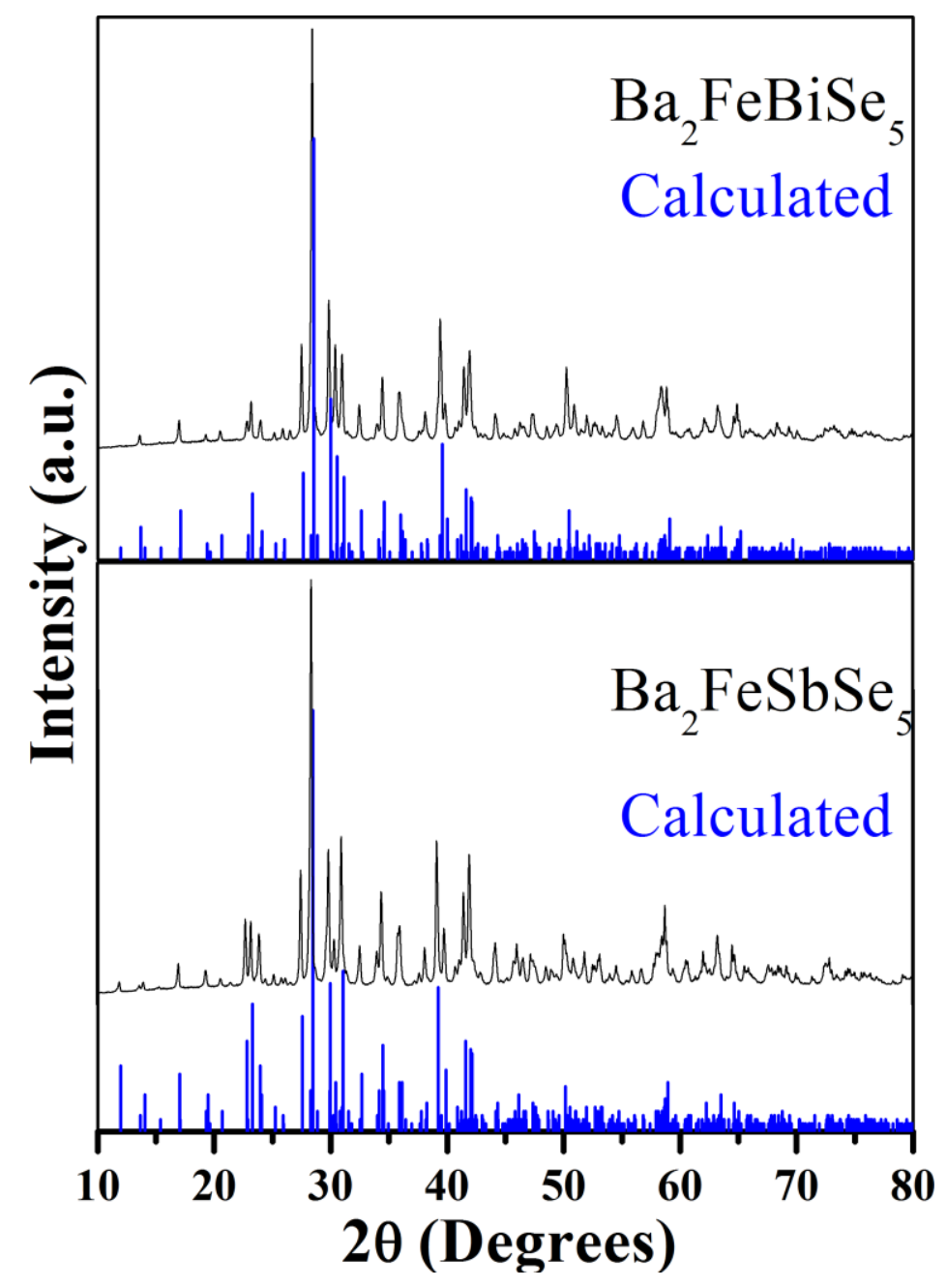


Figure 1. Powder X-ray diffraction patterns for $\mathrm{Ba}_{2} \mathrm{FeSbSe}_{5}$ and $\mathrm{Ba}_{2} \mathrm{FeSbSe}_{5}$ along with the corresponding calculated patterns.

Single-Crystal X-ray Diffraction. The data collections were performed under nitrogen gas atmosphere at $90 \mathrm{~K}$ using a Bruker SMART APEX-II diffractometer equipped with CCD area detector and graphite-monochromated Mo- $K_{\alpha}$ radiation $(\lambda=0.71073 \AA)$. Data reduction and integration, together with global unit cell refinements were performed in APEX2 software. ${ }^{[15]}$ Multiscan absorption corrections were applied. ${ }^{[15]}$ The structures were solved by direct methods and refined by full matrix least-squares methods on $F^{2}$ using the SHELX package with anisotropic displacement parameters for all atoms. ${ }^{[16]}$ In the last refinement cycles, the atomic positions for the two compounds were standardized using the program Structure TIDY. ${ }^{[17,18]}$ Details of the data collection and structure refinement are provided in Table 1. Atomic coordinates and selected bond distances are listed in Tables 2 and 3. Further information can be found in Fachinformationszentrum Karlsruhe, 76344 Eggenstein-Leopoldshafen, Germany, by quoting the depository CSD-number $430295\left(\mathrm{Ba}_{2} \mathrm{FeSbSe}_{5}\right)$ and $430296\left(\mathrm{Ba}_{2} \mathrm{FeBiSe}_{5}\right)$.

Powder X-ray Diffraction and Elemental Analysis. Powder X-ray diffraction (PXRD) analysis was performed at room temperature using a Rigaku Miniflex 600 diffractometer employing $\mathrm{Cu}-K_{\alpha}$ radiation with a $\mathrm{Ni}-K_{\beta}$ filter. Elemental analysis of selected crystals of $\mathrm{Ba}_{2} \mathrm{FePnSe}_{5}(\mathrm{Pn}=\mathrm{Sb}, \mathrm{Bi})$ was carried out on a Hitachi S4100T scanning electron microscope (SEM) with energy-dispersive X-ray (EDX) microanalysis (Oxford INCA Energy). The analyses confirmed the presence of only $\mathrm{Ba}, \mathrm{Fe}, \mathrm{Pn}$, and $\mathrm{Se}$ in the samples, and the observed elemental ratios are in good agreement with the compositions determined from single crystal X-ray diffraction experiments (Table S1). 
TG-DSC Measurements. Differential scanning calorimetry (DSC) analyses were conducted with a Netzsch differential 114 scanning calorimeter. Powder samples of $\mathrm{Ba}_{2} \mathrm{FeSbSe}_{5}$ (mass: $16.3 \mathrm{mg}$ ) and $\mathrm{Ba}_{2} \mathrm{FeBiSe}_{5}$ (mass: $12.9 \mathrm{mg}$ ) were sealed inside evacuated silica ampoules and heated to $1273 \mathrm{~K}$ at a rate of $10 \mathrm{~K} / \mathrm{min}$. Powder $\mathrm{x}$-ray diffraction patterns prior to and after thermal analysis experiments are shown in Figure S1.

Magnetic Measurements. Magnetic measurements were performed on polycrystalline samples placed in gelatin capsules. Magnetic susceptibility was measured in the temperature range from 2-300 $\mathrm{K}$ in an applied field of $10 \mathrm{mT}$, and isothermal magnetization measurements were performed at $5 \mathrm{~K}$ in an applied field of 0-7 $\mathrm{T}$ using a Quantum Design MPMS-XL SQUID magnetometer.

Resistivity measurements. The electrical resistivity was measured by a standard four-point alternating-current technique to exclude the resistance of the leads using a commercial multipurpose Physical Properties Measurement System (PPMS, Quantum Design). The resistivity measurements were performed on pieces of a polycrystalline melt of each compound, which were obtained by heating sample over the melting point and slowly cooling down. The polycrystalline sample of $\mathrm{Ba}_{2} \mathrm{FeSbSe}_{5}$ exhibited a shiny, regular surface, while the sample of $\mathrm{Ba}_{2} \mathrm{FeBiSe}_{5}$ appeared to have many voids and pores resulting in a much lower density, rendering it unsuitable for reliable resistivity measurements. Due to the high values of resistivity, close to the power limit of the instrument, the resistivity was only recorded from $300 \mathrm{~K}$ to $400 \mathrm{~K}$ for $\mathrm{Ba}_{2} \mathrm{FeSbSe}_{5}$ (Figure S2). 


\section{Results and Discussion}

\section{Synthesis and Thermal Stability}

The DSC characterization results for $\mathrm{Ba}_{2} \mathrm{FeSbSe}_{5}$ and $\mathrm{Ba}_{2} \mathrm{FeBiSe}_{5}$ are shown in Figure 2. $\mathrm{Ba}_{2} \mathrm{FeSbSe}_{5}$ melts congruently at $1055(5) \mathrm{K}$ and recrystallizes at 1001(5) $\mathrm{K}$. In turn, $\mathrm{Ba}_{2} \mathrm{FeBiSe}_{5}$ melts at a higher temperature of 1105(5) $\mathrm{K}$ and recrystallizes at 1049(5) $\mathrm{K}$. The samples were analyzed by PXRD after the DSC experiment, and there was no indication of decomposition or phase transition occurring upon melting and crystallization (Figure S1). The synthesis temperature profile involves heating samples close to or over the melting temperature to achieve better homogeneity. Afterwards slow cooling and additional annealing at lower temperature were applied to ensure complete reaction and to minimize strain or defects in the samples.

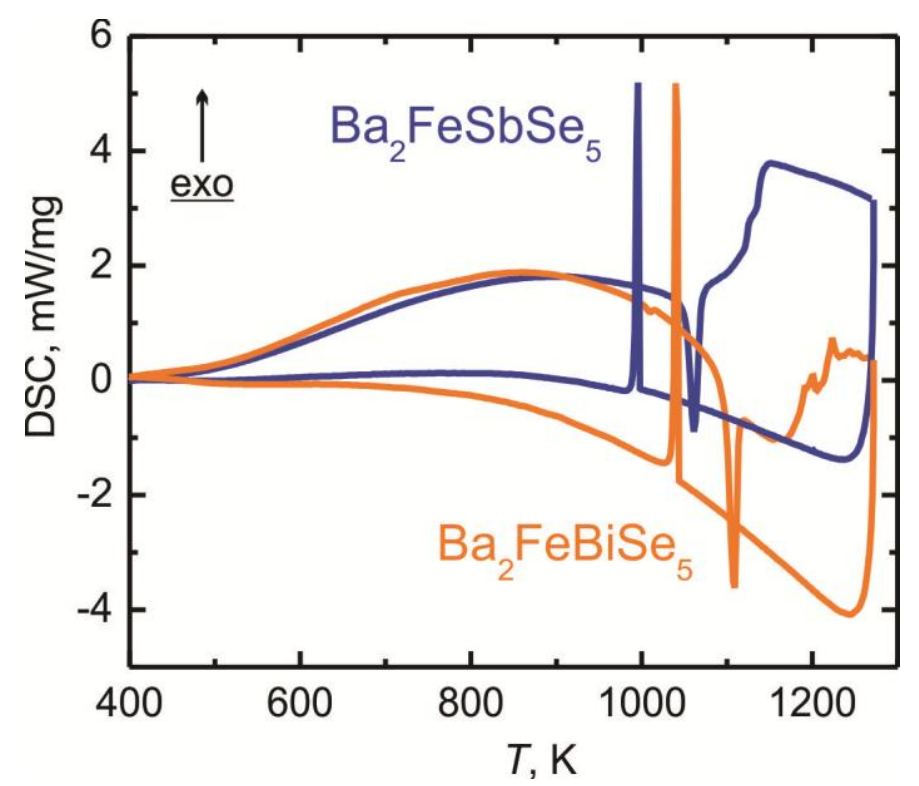

Figure 2. $\mathrm{DSC}$ results for $\mathrm{Ba}_{2} \mathrm{FeSbSe}_{5}$ (blue line) and $\mathrm{Ba}_{2} \mathrm{FeBiSe}_{5}$ (orange line).

\section{Structure Description}

The title compounds $\mathrm{Ba}_{2} \mathrm{FeSbSe}_{5}$ and $\mathrm{Ba}_{2} \mathrm{FeBiSe}_{5}$ are isostructural, and both are isomorphic to the high pressure phase $\mathrm{Ba}_{3} \mathrm{FeS}_{5} \cdot{ }^{[19]}$ Furthermore, the sulfur-containing analogues $\mathrm{Ba}_{2} \mathrm{FePnS}_{5}(\mathrm{Pn}$ 
$=\mathrm{Sb}, \mathrm{Bi})^{[20]}$ as well as isostructural compounds where $\mathrm{Fe}^{3+}$ is replaced with $\mathrm{Ga}^{3+}, \mathrm{Ba}_{2} \mathrm{GaPnSe}_{5}$ $(\mathrm{Pn}=\mathrm{Sb}, \mathrm{Bi}),{ }^{[21]}$ have also been reported. Due to structural similarities, only $\mathrm{Ba}_{2} \mathrm{FeBiSe}_{5}$ is discussed below, for which the crystal structure is shown in Figure 3. The main building blocks are distorted $\mathrm{BiSe}_{6}$ octahedra, $\mathrm{FeSe}_{4}$ tetrahedra, and $\mathrm{BaSe}_{8}$ polyhedra (Figure 3 top). The $\mathrm{BiSe}_{6}$ octahedra are strongly distorted in such a way that the $\mathrm{Bi}$ atom is displaced from the center of the octahedron, forming three short $(<2.8 \AA$ ) and three long ( $>3.2 \AA$ ) Bi-Se bonds (Table 3 ). This is common for the $\mathrm{Bi}^{3+}$ cation with an active electron lone pair. ${ }^{[20,21]}$ Each $\mathrm{BiSe}_{6}$ octahedron is fused to four $\mathrm{FeSe}_{4}$ tetrahedra by sharing three vertices and one edge. In addition, the $\mathrm{BiSe}_{6}$ octahedra share two opposite edges with other $\mathrm{BiSe}_{6}$ octahedra, forming a chain running along the [010] direction (Figure 3 middle). These chains are connected to each other through the $\mathrm{FeSe}_{4}$ tetrahedra, which share one vertex and one edge with two $\mathrm{BiSe}_{6}$ octahedra from different chains. The Ba cations are located in the large channels (Figure 3 bottom).

The Fe-Se bond distances in $\mathrm{Ba}_{2} \mathrm{FePnSe}_{5}(2.33-2.41 \AA)$ are slightly shorter than those in compounds containing $\mathrm{Fe}^{\mathrm{II}} \mathrm{Se}_{4}$ tetrahedral building blocks where $\mathrm{Fe}$ is in a formal oxidation state of +2 , such as FeSe $\left.(2.39 \AA),{ }^{[22,23]} \mathrm{K}_{2} \mathrm{Fe}_{4} \mathrm{Se}_{5}(2.44-2.51 \AA),{ }^{[24]}\left(\mathrm{Li}_{1-x} \mathrm{Fe}_{x}\right) \mathrm{OHFeSe}(2.44) \AA\right),{ }^{[3]}$ but these distances are similar to those found in $\mathrm{Fe}^{\mathrm{III}} \mathrm{Se}_{4}$ tetrahedra. ${ }^{[4,5,25]}$ The bond distances in the $\mathrm{PnSe}_{6}$ octahedra are 2.67-3.30 $\AA$ for $\mathrm{Pn}=\mathrm{Bi}$ and 2.57-3.31 $\AA$ for $\mathrm{Pn}=\mathrm{Sb}$. The Ba cations are coordinated by eight Se atoms with Ba-Se distances in the range of 3.35-3.46 $\AA$, which are comparable to those in $\mathrm{BaPn}_{2} \mathrm{Se}_{4}{ }^{[26]}$ and $\mathrm{Ba}_{2} \mathrm{GaPnSe}_{5}{ }^{[21]}(\mathrm{Pn}=\mathrm{Sb}, \mathrm{Bi})$. 


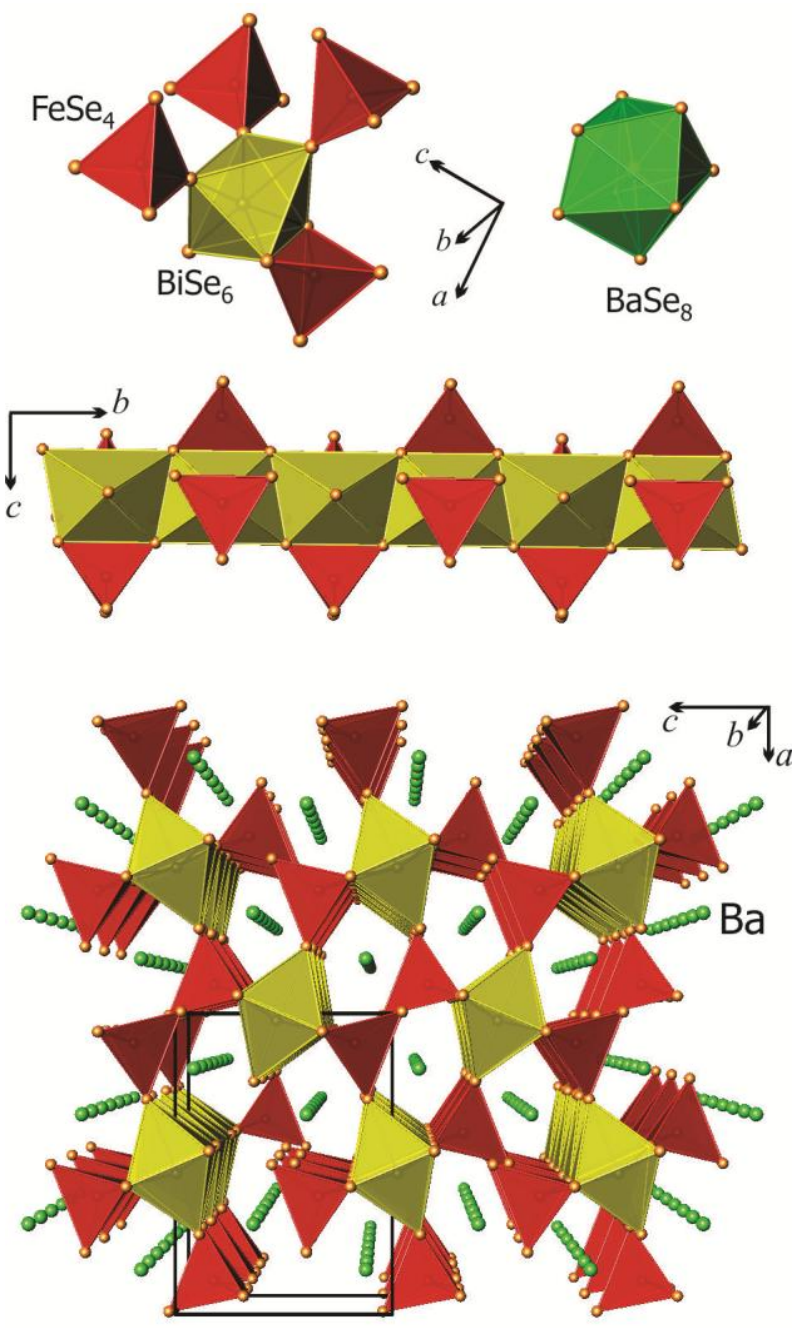

Figure 3. The crystal structure of $\mathrm{Ba}_{2} \mathrm{FeBiSe}_{5}$ : (top) $\mathrm{BiSe}_{6}$ octahedron (yellow) surrounded by four $\mathrm{FeSe}_{4}$ tetrahedra (red), and an isolated $\mathrm{BaSe}_{8}$ polyhedron (green); (middle) a linear chain of $\mathrm{BiSe}_{6}$ octahedra running along [010]; (bottom) a general view of the crystal structure viewed along [010]. Ba: green; Se: orange. Unit cell is shown as black lines.

In both compounds iron is in the +3 formal oxidation state, according to the results of magnetic measurements and reports for isostructural S- and Ga-containing compounds. ${ }^{[20,21]}$ Thus, these two compounds are charge-balanced phases and their composition can be rationalized as 
$\left[\mathrm{Ba}^{2+}\right]_{2}\left[\mathrm{Fe}^{3+}\right]_{1}\left[\mathrm{Pn}^{3+}\right]_{1}\left[\mathrm{Se}^{2-}\right]_{5}$. The charge-balanced nature of $\mathrm{Ba}_{2} \mathrm{FePnSe}_{5}(\mathrm{Pn}=\mathrm{Sb}, \mathrm{Bi})$ is also demonstrated by the large values of the electrical resistivity (74 and $314 \Omega \cdot \mathrm{m}$ at $400 \mathrm{~K}$ for $\mathrm{Ba}_{2} \mathrm{FeSbSe}_{5}$ and $\mathrm{Ba}_{2} \mathrm{FeBiSe}_{5}$, respectively), which increased with decreasing temperature. These values are comparable to the resistivity of our previously reported charge-balanced compound $\mathrm{Ba}_{2} \mathrm{Sb}_{2} \mathrm{Se}_{5}$, which had a resistivity of $70 \Omega \cdot \mathrm{m}$ at $400 \mathrm{~K} .^{[14]}$

\section{Magnetic Properties.}

The temperature dependence of the magnetic susceptibilities for $\mathrm{Ba}_{2} \mathrm{FePnSe}_{5}(\mathrm{Pn}=\mathrm{Sb}$ or $\mathrm{Bi})$ are shown in Figure 4. No significant differences for ZFC and FC curves were detected. Both compounds exhibited an antiferromagnetic ordering at $T_{\mathrm{N}}=58(1) \mathrm{K}(\mathrm{Sb})$ and $T_{\mathrm{N}}=79(2) \mathrm{K}(\mathrm{Bi})$. For both compounds the antiferromagnetic peaks are quite broad, and significant deviations from linearity were observed in the inverse magnetic susceptibility $\left(\chi^{-1}\right)$ at temperatures below $100 \mathrm{~K}$. To ensure that the broadness was not the result of disorder or defects, both samples were reannealed at $900 \mathrm{~K}$ for 5 days. The re-annealed samples exhibited similar magnetic properties.

The results of the Curie-Weiss fit of $\chi^{-1}$ at temperatures at least $70 \mathrm{~K}$ higher than $T_{\mathrm{N}}$ are shown in the corresponding insets in Figure 4. The effective magnetic moments of the $\mathrm{Fe}$ ions in $\mathrm{Ba}_{2} \mathrm{FeSbSe}_{5}$ and $\mathrm{Ba}_{2} \mathrm{FeBiSe}_{5}$ are calculated to be 5.3(1) $\mu_{\mathrm{B}}$ and 6.0(1) $\mu_{\mathrm{B}}$, respectively, which are close to the theoretical value of a high-spin $\mathrm{Fe}^{3+}$ ion $\left(S=5 / 2, L=0,5.92 \mu_{\mathrm{B}}\right)$. The lower moment for the Sb-containing compound may be due to the presence of an unidentified amorphous admixture in the sample. The Weiss constants $(\theta)$ for both phases are negative, indicating antiferromagnetic next-neighbor interactions. In absolute values the Weiss constants are almost twice as large as $T_{\mathrm{N}}: \theta=-125(1) \mathrm{K}(\mathrm{Sb})$ and $\theta=-135(1) \mathrm{K}(\mathrm{Bi})$, suggesting that certain degree of frustration is present in both compounds. 


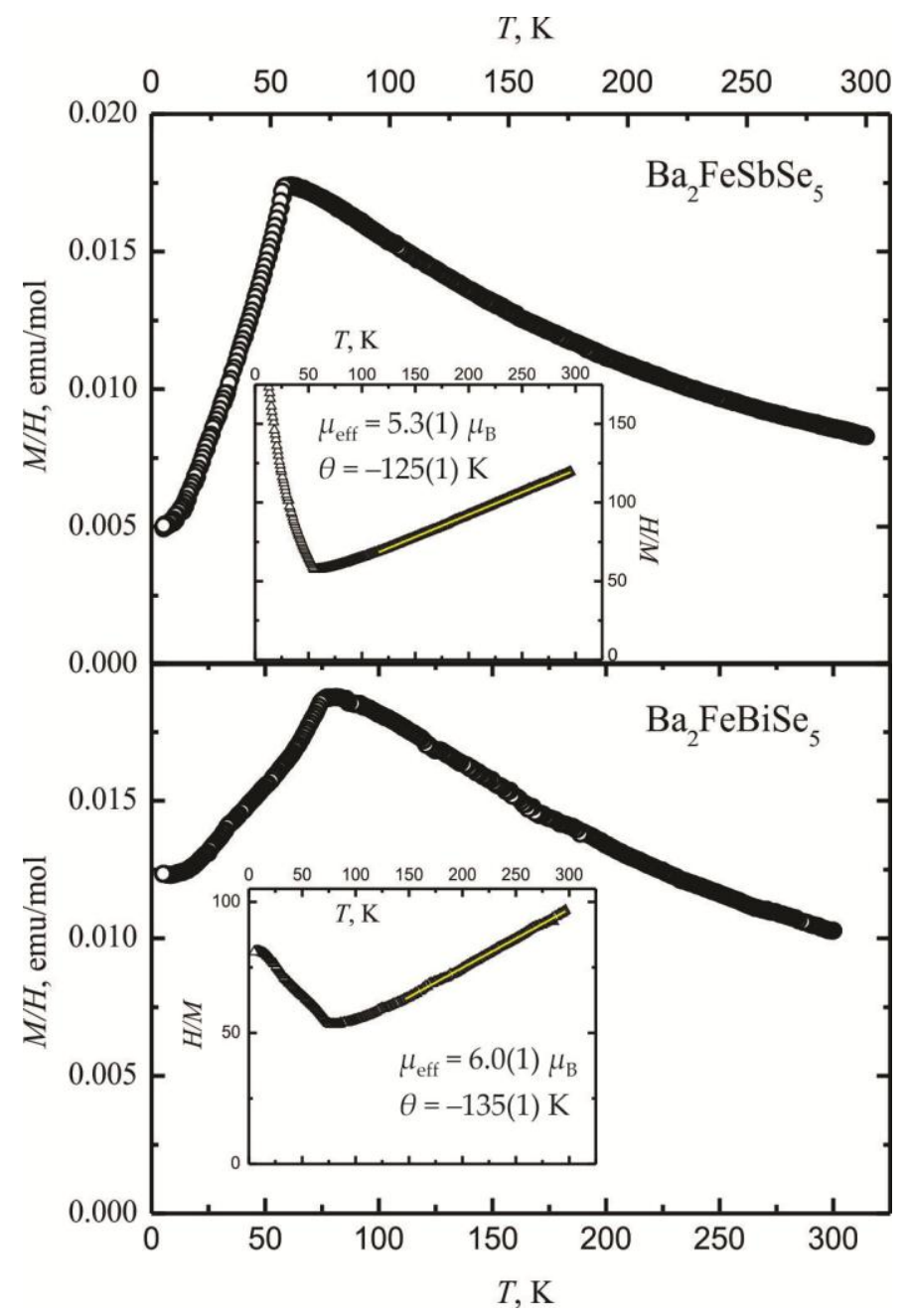

Figure 4. Temperature-dependent magnetic susceptibilities for $\mathrm{Ba}_{2} \mathrm{FeSbSe}_{5}$ (top) and $\mathrm{Ba}_{2} \mathrm{FeBiSe}_{5}$ (bottom) measured in an applied field of $0.01 \mathrm{~T}$. Insets: Inverse magnetic susceptibility as a function of temperature together with a linear Curie-Weiss fit (yellow lines).

The isothermal magnetizations of $\mathrm{Ba}_{2} \mathrm{FeSbSe}_{5}$ and $\mathrm{Ba}_{2} \mathrm{FeBiSe}_{5}$ as a function of applied field were measured at $5 \mathrm{~K}$ (Figure 5). The almost linear increase of the magnetization with the applied field and the low total moment further support the presence of antiferromagnetic interactions between $\mathrm{Fe}$ centers in both compounds. However, distinct changes in the slopes of the curves are visible between 0.2-0.3 $\mathrm{T}$ for the Sb-containing compound (Figure 5 inset) and 
2.5-3 T for the Bi-containing compound (Figure 5). A metamagnetic-like transition was observed at $0.2 \mathrm{~T}$ for the $\mathrm{Sb}$-containing compound, which may indicate the presence of a low-lying excited state which could explain the reduced $\mathrm{Fe}$ moment observed from the Curie-Weiss fit. Comprehensive neutron diffraction investigations are required to further clarify the magnetic structure of the reported compounds.

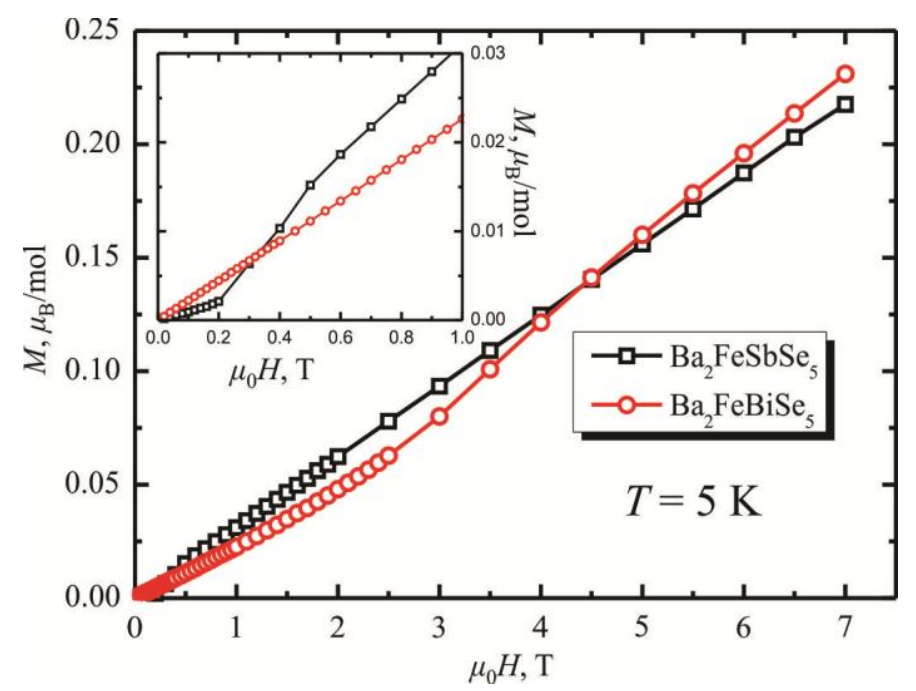

Figure 5. Isothermal field dependence of magnetization for $\mathrm{Ba}_{2} \mathrm{FeSbSe}_{5}$ (black) and $\mathrm{Ba}_{2} \mathrm{FeBiSe}_{5}$ (red). The low field region is shown in the inset. The lines are drawn to guide the eyes.

Two sulfur-containing analogues also exhibit an antiferromagnetic ordering, but at much lower temperatures, $T_{\mathrm{N}}=13 \mathrm{~K}\left(\mathrm{Ba}_{2} \mathrm{FeSbS}_{5}\right)$ and $T_{\mathrm{N}}=35 \mathrm{~K}\left(\mathrm{Ba}_{2} \mathrm{FeBiS}_{5}\right) .{ }^{[20]}$ The antiferromagnetic peaks are also much sharper for the S-containing compounds. These observations rule out a possibility of any direct magnetic interactions between $\mathrm{Fe}$ centers, as the shortest $\mathrm{Fe}-\mathrm{Fe}$ distance increases when switching from $\mathrm{S}(5.8 \AA)$ to $\mathrm{Se}(6.0 \AA)$. All four compounds are charge-balanced with empty conduction bands, which also rules out the possibility of RKKY interactions. One possible mechanism for magnetic interactions is a kind of superexchange involving Fe-Se-Pn-Se$\mathrm{Fe}(\mathrm{Pn}=\mathrm{Sb}, \mathrm{Bi})$ pathways (Figure 6, A-B pathway). The angles $\angle \mathrm{Fe}-\mathrm{Se}-\mathrm{Pn}$ for the $\mathrm{FeSe}_{4}$ 
tetrahedra sharing a vertex with $\mathrm{PnSe}_{6}$ octahedra are in the range of $171-174^{\circ}$, while those sharing an edge have $\angle \mathrm{Fe}$-Se-Pn angles of $81^{\circ}$. The distance between centers of $\mathrm{A}$ and $\mathrm{B} \mathrm{FeSe}{ }_{4}$ tetrahedra is $6.48 \AA$. Another possibility for the shorter Fe-Fe separation of $6.04 \AA$ includes barium atoms, i.e. Fe-Se-Ba-Se-Fe interactions (Figure 6, pathway A-C).

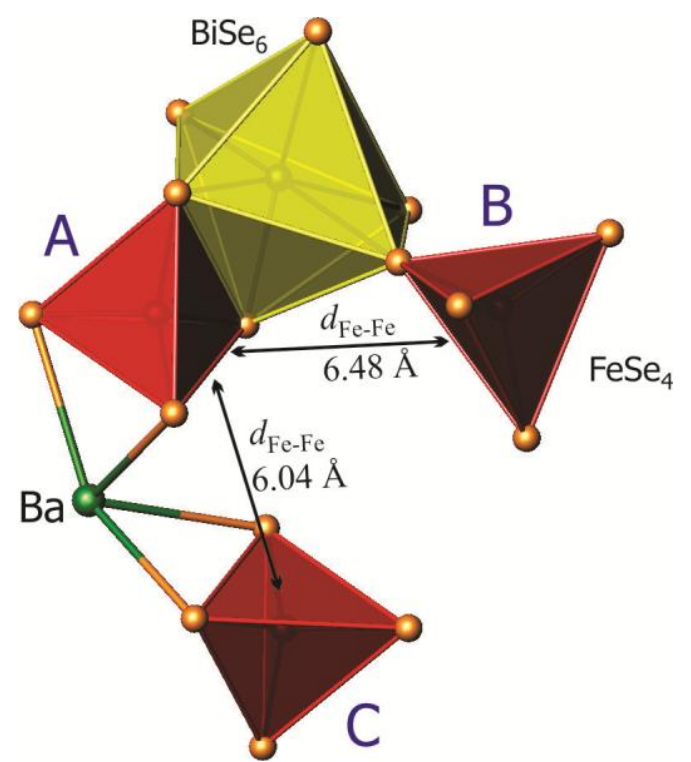

Figure 6. Two possible magnetic exchange pathways are shown in this portion of the crystal structure of $\mathrm{Ba}_{2} \mathrm{FeBiSe}_{5}$. The first connects the Fe atoms in the centers of tetrahedra $\mathrm{A}$ and $\mathrm{B}$ via the pathway $\mathrm{Fe}-\mathrm{Se}-\mathrm{Bi}-\mathrm{Se}-\mathrm{Fe}$; the second connects the $\mathrm{Fe}$ atoms in tetrahedra $\mathrm{A}$ and $\mathrm{C}$ via the pathway Fe-Se-Ba-Se-Fe. BiSe ${ }_{6}$ octahedron: yellow; $\mathrm{FeSe}_{4}$ tetrahedra: red; Ba: green; Se: orange.

The higher ordering temperatures for the Se-containing compounds may be explained by the higher degree of delocalization present compared to the more ionic bonding character in the S-containing analogues. The magnetic superexchange through long non-magnetic bridges is rare, but not unknown. In the molecular cyanides the superexchange through even longer bridges of $\mathrm{M}-\mathrm{N} \equiv \mathrm{C}-\mathrm{M}^{\prime}-\mathrm{C} \equiv \mathrm{N}-\mathrm{M}$ type have been reported for cases where $\mathrm{M}^{\prime}$ is a non-magnetic metal such as $\mathrm{Zn}^{2+}$ or low spin $\mathrm{Fe}^{2+} \cdot{ }^{[27]}$ In ordered Os-containing double perovskites, such as $\mathrm{Sr}_{2} \mathrm{MgOsO}_{6}$ and 
$\mathrm{Ba}_{2} \mathrm{YOsO}_{6}$ where the Os atoms are separated by long O-Mg-O or O-Y-O bridges, antiferromagnetic orderings at temperatures above $60 \mathrm{~K}$ were reported. ${ }^{[28,29]}$ For $3 d$ transition metals double perovskites, where magnetic metals are separated by $\mathrm{O}-\mathrm{W}^{6+}-\mathrm{O}$ groups, slightly lower antiferromagnetic ordering temperatures were reported, such as $T_{\mathrm{N}}=37 \mathrm{~K}$ for $\mathrm{Sr}_{2} \mathrm{FeWO}_{6} \cdot{ }^{[30]}$

\section{Conclusions}

Two quaternary magnetic semiconductors, $\mathrm{Ba}_{2} \mathrm{FeSbSe}_{5}$ and $\mathrm{Ba}_{2} \mathrm{FeBiSe}_{5}$, have been synthesized by high temperature solid state reactions. Both compounds crystallize in the orthorhombic Pnma space group, isomorphic to the high pressure phase $\mathrm{Ba}_{3} \mathrm{FeS}_{5}$. Magnetic characterization indicates antiferromagnetic interactions between high spin $\mathrm{Fe}^{3+}$ centers which results in an antiferromagnetic ordering. A magnetic superexchange mediated either by $\mathrm{Se}-\mathrm{Pn}-\mathrm{Se}(\mathrm{Pn}=\mathrm{Sb}$, $\mathrm{Bi}$ ) or Se-Ba-Se bridges is suggested as a possible mechanism for magnetic interactions in these charge-balanced compounds.

\section{Acknowledgements}

Authors would like to thank Kathleen Lee for help with EDX measurements and Prof. Susan Kauzlarich for access to DSC. This research is supported by the U.S. Department of Energy, Office of Basic Energy Sciences, Division of Materials Sciences and Engineering under Award DE-SC0008931.

\section{References}


[1] (a) F-C. Hsu, J-Y. Luo, K-W. Yeh, T-K. Chen, T-W. Huang, P. M. Wu, Y-C. Lee, Y-L. Huang, Y-Y. Chu, D-Ch. Yan, M-Ku. Wu, Proc. Natl. Acad. Sci. U. S. A. 105 (2008) 1426214264. (b) S. L. He, J. F. He, W. H. Zhang, L. Zhao, D. F. Liu, X. Liu, D. X. Mou, Y. B. Ou, Q. Y. Wang, Z. Li, L. L. Wang, Y. Y. Peng, Y. Liu, C. Y. Chen, L. Yu, G. D. Liu, X. L. Dong, J. Zhang, C. T. Chen, Z. Y. Xu, X. Chen, X. Ma, Q. K. Xue, X. J. Zhou, Nat. Mater. 12 (2013) 605610.

[2] (a) J. Guo, S. Jin, G. Wang, S. Wang, K. Zhu, T. Zhou, M. He, X. Chen, Phys. Rev. B.82 (2010) 180520. (b) T. P. Ying, X. L. Chen, G. Wang, S. F. Jin, T. T. Zhou, X. F. Lai, H. Zhang, W. Y. Wang, Sci Rep. 2 (2012) 426. (c) M. Burrard-Lucas, D. G. Free, S. J. Sedlmaier, J. D. Wright, S. J. Cassidy, Y. Hara, A. J. Corkett, T. Lancaster, P. J. Baker, S. J. Blundell, S. J. Clarke, Nat. Mater.12 (2013) 15-19.

[3] X. Dong, H. Zhou, H. Yang, J. Yuan, K. Jin, F. Zhou, D. Yuan, L. W, J. Li, X. Wang, G. Zhang, Z. Zhao. J. Am. Chem. Soc. 137 (2015) 66-69.

[4] C. Pak, S. Kamali, J. Pham, K. Lee, J. T. Greenfield, K. Kovnir, J. Amer. Chem. Soc. 135 (2013) 19111-19114.

[5] J. T. Greenfield, C. Pak, S. Kamali, K. Lee, K. Kovnir, Chem. Commun. 51 (2015) 53555358.

[6] D.-Y. Chung, T. Hogan, P. Brazis, M. Rocci-Lane, C. Kannewurf, M. Bastea, C. Uher, M. G. Kanatzidis, Science 287 (2000) 1024-1027.

[7] K. F. Hsu, S. Loo, F. Guo, W. Chen, J. S. Dyck, C. Uher, T. Hogan, E. K. Polychroniadis, M. G. Kanatzidis, Science 303 (2004) 818-821.

[8] Y. S. Zh, V. Ozoliņš, D. Morelli, C. Wolverton, Chem. Mater. 26 (2014) 3427-3435.

[9] K. Tyagi, B. Gahtori, S. Bathula, A. K. Srivastava, A. K. Shukla, S. Aulucka, A. Dhar, J. Mater. Chem. A 2 (2014) 15829-15835.

[10] W. J. Qiu, L. L. Xi, P. Wei, X. Z. Ke, J. H. Yang, W. Q. Zh, Proc. Natl. Acad. Sci. U. S. A. 111 (2014) 15031-15035. 
[11] M. G. Kanatzidis, T. J. McCarthy, T. A. Tanzer, L.-H. Chen, L. Iordanidis, Chem. Mater. 8 (1996) 1465-1474.

[12] I. Chung, M. G. Kanatzidis, Chem. Mater. 26 (2014) 849-869.

[13] J. Wang, K. Kovnir, Z. Anorg. Allg. Chem. 641 (2015) 1087-1092.

[14] J. Wang, K. Lee, K. Kovnir, J. Mater. Chem. C 3 (2015) 9811-9818.

[15] Bruker APEX2; Bruker AXS Inc.: Madison, WI, 2005.

[16] G.M. Sheldrick, Acta Crystallogr. A64 (2008) 112-122.

[17] E. Parthé, L. M. Gelato, Acta Crystallogr. A40 (1984) 169.

[18] L. M. Gelato, E. Parthé, J. Appl. Crystallogr. 20 (1987) 139.

[19] J. T. Lemley, J. M. Jenks, J. T. Hoggins, Z. Eliezer, H. Steinfink, J. Solid State Chem. 16 (1976) $117-128$.

[20] L. Geng, W-D. Cheng, H. Zhang, C-S. Lin, W-L. Zhang, Y-Y. Li,Z-Z. He, Inorg. Chem. 50 (2011) 2378-2384.

[21] W. Hao, D. Mei, W. Yin, K. Feng, J. Yao, Y. Wu, J. Solid State Chem.198 (2013) 81-86.

[22] C. Koz, M. Schmidt, H. Borrmann, U. Burkhardt, S.Rößler, W. Carrillo-Cabrera, W. Schnelle, U. Schwarz, Y. Grin, Z. Anorg. Allg. Chem. 640 (2014) 1600-1606.

[23] J. T. Greenfield, S. Kamali, K. Lee, K. Kovnir, Chem. Mater. 27 (2015) 588-596.

[24] J. Bacsa, A. Y. Ganin, Y. Takabayashi, K. E. Christensen, K. Prassides, M. J. Rosseinsky, J. B. Claridge, Chem. Sci. 2 (2011) 1054-1058.

[25] W. Bronger, A. Kyas, P. Mueller, J. Solid State Chem. 70 (1987) 262-270.

[26] (a) G. Cordier, H. Schaefer, Z. Naturforsch. B. 34 (1979) 1053-1056. (b) L. Iordanidis, P. W. Brazis, T. Kyratsi, J. Ireland, M. Lane, C. R. Kannewurf, W. Chen, J. S. Dyck, C. Uher, N. Ghelani, T. Hogan, M.G. Kanatzidis, Chem. Mater. 13 (2001) 622-633.

[27] M. Shatruk, C. Avenado, K.R. Dunbar, Prog. Inorg. Chem. 56 (2009) 155-334. 
[28] Y. Yuan, H.L. Feng, M.P. Ghimire, Y. Matsushita, Y. Tsujimoto, J. He, M. Tanaka, Y. Katsuya, K. Yamaura, Inorg. Chem. 54, (2015) 3422-3431.

[29] E. Kermarrec, C.A. Marjerrison, C.M. Thompson, D.D. Maharaj, K. Levin, S. Kroeker, G.E. Granroth, R. Flacau, Z. Yamani, J.E. Greedan, B.D. Gaulin, Phys. Rev. B 91 (2015) 075133/1075133/9.

[30] K. Kawanaka, I. Hase, S. Toyama, Y. Nishihara, J. Phys. Soc. Jpn. 68 (1999) 2890-2893. 
Table 1. Selected crystal data and structure refinement parameters for $\mathrm{Ba}_{2} \mathrm{PnSbSe}_{5}$.

\begin{tabular}{|c|c|c|}
\hline Empirical formula & $\mathrm{Ba}_{2} \mathrm{FeSbSe}_{5}$ & $\mathrm{Ba}_{2} \mathrm{FeBiSe}_{5}$ \\
\hline Formula weight & $847.08 \mathrm{~g} / \mathrm{mol}$ & $934.31 \mathrm{~g} / \mathrm{mol}$ \\
\hline CSD-number & 430295 & 430296 \\
\hline Temperature & \multicolumn{2}{|c|}{$90(2) \mathrm{K}$} \\
\hline Radiation, wavelength & \multicolumn{2}{|c|}{ Mo- $K_{\alpha}, 0.71073 \AA$} \\
\hline Crystal system & \multicolumn{2}{|c|}{ Orthorhombic } \\
\hline Space group & \multicolumn{2}{|c|}{ Pnma (No. 62) } \\
\hline \multirow[t]{3}{*}{ Unit cell dimensions } & $a=12.603(2) \AA$ & $a=12.619(2) \AA$ \\
\hline & $b=9.106(1) \AA$ & $b=9.183(1) \AA$ \\
\hline & $c=9.145(1) \AA$ & $c=9.123(1) \AA$ \\
\hline Unit cell volume & $1049.5(2) \AA^{3}$ & $1057.1(2) \AA^{3}$ \\
\hline$Z$ & & \\
\hline$\rho_{\text {calc }}$ & $5.36 \mathrm{~g} / \mathrm{cm}^{3}$ & $5.87 \mathrm{~g} / \mathrm{cm}^{3}$ \\
\hline Absorption coefficient & $28.57 \mathrm{~mm}^{-1}$ & $42.43 \mathrm{~mm}^{-1}$ \\
\hline Data/param. & $1147 / 50$ & $1696 / 50$ \\
\hline$R$ values $^{\mathrm{a}}$ & $R_{1}=0.019$ & $R_{1}=0.027$ \\
\hline$\left[I>2 \sigma_{(I)}\right]$ & $w R_{2}=0.031$ & $w R_{2}=0.039$ \\
\hline$R$ values $^{\mathrm{a}}$ & $R_{1}=0.024$ & $R_{1}=0.046$ \\
\hline [all data] & $w R_{2}=0.033$ & $w R_{2}=0.043$ \\
\hline
\end{tabular}
Goodness-of-fit
1.10
0.99

$\mathrm{R}_{1}=\sum|| \mathrm{F}_{\mathrm{o}}|-| \mathrm{F}_{\mathrm{c}}\left|/ \sum\right| \mathrm{F}_{\mathrm{o}} \mid ; \quad \mathrm{wR}_{2}=\left[\sum\left[\mathrm{w}\left(\mathrm{F}_{\mathrm{o}}{ }^{2}-\mathrm{F}_{\mathrm{c}}{ }^{2}\right)^{2}\right] / \sum\left[\mathrm{w}\left(\mathrm{F}_{\mathrm{o}}{ }^{2}\right)^{2}\right]\right]^{1 / 2}$, and $\mathrm{w}=1 /\left[\sigma^{2} \mathrm{~F}_{\mathrm{o}}{ }^{2}+(\mathrm{A} \cdot \mathrm{P})^{2}+\right.$ $\mathrm{B} \cdot \mathrm{P}], \mathrm{P}=\left(\mathrm{F}_{\mathrm{o}}^{2}+2 \mathrm{~F}_{\mathrm{c}}^{2}\right) / 3 ; \mathrm{A}$ and $\mathrm{B}$ are weight coefficients. 
Table 2. Refined atomic coordinates and displacement parameters for $\mathrm{Ba}_{2} \mathrm{FePnSe}_{5}$.

\begin{tabular}{|c|c|c|c|c|c|c|}
\hline Atoms & Wyckoff & $x / a$ & $y / b$ & $z / c$ & S.O.F. & $U_{\text {eq }}\left(\AA^{2}\right)^{a}$ \\
\hline \multicolumn{7}{|c|}{$\mathrm{Ba}_{2} \mathrm{FeSbSe}_{5}$} \\
\hline $\mathrm{Ba} 1$ & $8 d$ & $0.32433(2)$ & $0.00782(3)$ & $0.37697(3)$ & 1 & $0.00502(8)$ \\
\hline $\mathrm{Fe} 1$ & $4 c$ & $0.09741(8)$ & $1 / 4$ & $0.1667(1)$ & 1 & $0.0050(2)$ \\
\hline Sb1 & $4 c$ & $0.02780(4)$ & $1 / 4$ & $0.51266(5)$ & 1 & $0.0054(1)$ \\
\hline Se1 & $8 d$ & $0.05766(4)$ & $0.03941(5)$ & $0.31671(5)$ & 1 & $0.0055(1)$ \\
\hline $\mathrm{Se} 2$ & $4 c$ & $0.21758(5)$ & $1 / 4$ & $0.61669(8)$ & 1 & $0.0052(2)$ \\
\hline $\mathrm{Se} 3$ & $4 c$ & $0.27986(5)$ & $1 / 4$ & $0.10764(8)$ & 1 & $0.0053(2)$ \\
\hline $\mathrm{Se} 4$ & $4 c$ & $0.49247(5)$ & $1 / 4$ & $0.54374(8)$ & 1 & $0.0054(2)$ \\
\hline \multicolumn{7}{|c|}{$\mathrm{Ba}_{2} \mathrm{FeBiSe}_{5}$} \\
\hline $\mathrm{Ba} 1$ & $8 d$ & $0.32385(3)$ & $0.00879(4)$ & $0.38186(4)$ & 1 & $0.00492(9)$ \\
\hline $\mathrm{Fe} 1$ & $4 c$ & $0.0972(1)$ & $1 / 4$ & $0.1684(1)$ & 1 & $0.0049(3)$ \\
\hline Bi1 & $4 c$ & $0.02334(3)$ & $1 / 4$ & $0.52386(4)$ & 1 & $0.00520(8)$ \\
\hline $\mathrm{Se} 1$ & $8 d$ & $0.05843(5)$ & $0.03738(7)$ & $0.31296(7)$ & 1 & $0.0052(1)$ \\
\hline $\mathrm{Se} 2$ & $4 c$ & $0.22159(7)$ & $1 / 4$ & $0.6258(1)$ & 1 & $0.0051(2)$ \\
\hline $\mathrm{Se} 3$ & $4 c$ & $0.28059(7)$ & $1 / 4$ & $0.1111(1)$ & 1 & $0.0055(2)$ \\
\hline $\mathrm{Se} 4$ & $4 c$ & $0.49394(6)$ & $1 / 4$ & $0.5441(1)$ & 1 & $0.0054(2)$ \\
\hline
\end{tabular}

${ }^{a} U_{\text {eq }}$ is defined as one third of the trace of the orthogonalized $U_{\mathrm{ij}}$ tensor 
Table 3. Selected interatomic distances $(\AA)$ in $\mathrm{Ba}_{2} \mathrm{FePnSe}_{5}$.

\begin{tabular}{|c|c|c|c|}
\hline Atom pairs & Distances $(\AA)$ & Atom pairs & Distances $(\AA)$ \\
\hline \multicolumn{4}{|c|}{$\mathrm{Ba}_{2} \mathrm{FeSbSe}_{5}$} \\
\hline \multirow[t]{8}{*}{$\mathrm{Ba} 1-$} & $3.4448(7)$ & $\mathrm{Fe} 1-\mathrm{Se} 1 \times 2$ & $2.4105(8)$ \\
\hline & $3.4179(7)$ & $\mathrm{Se} 3$ & $2.362(1)$ \\
\hline & $3.3848(7)$ & $\mathrm{Se} 4$ & $2.335(1)$ \\
\hline & $3.3882(7)$ & $\mathrm{Sb} 1-\mathrm{Se} 1 \times 2$ & $2.6514(6)$ \\
\hline & $3.3533(7)$ & $\operatorname{Se} 1 \times 2$ & $3.2467(6)$ \\
\hline & $3.4186(6)$ & $\mathrm{Se} 2$ & $2.5740(9)$ \\
\hline & $3.3716(6)$ & $\mathrm{Se} 3$ & $3.3128(9)$ \\
\hline & $3.4176(7)$ & & \\
\hline \multicolumn{4}{|c|}{$\mathrm{Ba}_{2} \mathrm{FeBiSe}_{5}$} \\
\hline $\mathrm{Ba} 1-\mathrm{Se} 1$ & $3.4180(8)$ & $\mathrm{Fe} 1-\mathrm{Se} 1 \times 2$ & $2.406(1)$ \\
\hline $\mathrm{Se} 1$ & $3.4627(8)$ & $\mathrm{Se} 3$ & $2.373(2)$ \\
\hline $\mathrm{Se} 2$ & $3.3815(8)$ & $\mathrm{Se} 4$ & $2.336(2)$ \\
\hline $\mathrm{Se} 2$ & $3.3944(8)$ & $\mathrm{Bi} 1-\mathrm{Se} 1 \times 2$ & $2.7767(7)$ \\
\hline $\mathrm{Se} 3$ & $3.3625(9)$ & $\mathrm{Se} 1 \times 2$ & $3.2008(7)$ \\
\hline $\mathrm{Se} 3$ & $3.4289(8)$ & $\mathrm{Se} 2$ & $2.669(1)$ \\
\hline $\mathrm{Se} 4$ & $3.3749(8)$ & $\mathrm{Se} 3$ & $3.301(1)$ \\
\hline $\mathrm{Se} 4$ & $3.4213(8)$ & & \\
\hline
\end{tabular}


Table of Contents Graphic

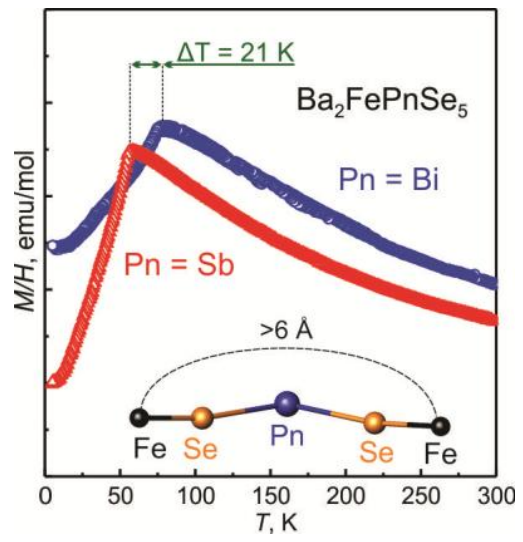

